\title{
Incorporation of Computational Fluid Dynamics into a Fluid Mechanics Curriculum
}

\author{
Desmond Adair
}

Additional information is available at the end of the chapter

http://dx.doi.org/10.5772/39217

\section{Introduction}

In this chapter, the development, implementation and evaluation of a suitable curriculum for students to use computational fluid dynamics (CFD) as part of a fluid mechanics course at intermediate undergraduate level are described. CFD is the simulation of fluids, heat transfer, etc., using modelling, that is, mathematical physical problem formulation, and numerical methods which includes, discretization methods, solvers, numerical parameters, and grid generation. Historically only Analytical Fluid Dynamics (AFD) and Experimental Fluid Dynamics (EFD) have been taught at the undergraduate level but inclusion of CFD is now possible and desirable, with the advancing improvements of computer resources.

The use of simulation can now be found in many areas of engineering education, for example for electronics laboratories (Campbell et al. 2004; Feisel \& Rosa, 2002), for chemical reactions (Qian and Tinker, 2006) and for diesel engine simulation (Assanis \& Heywood, 1986). Simulation has also been effective in fluid mechanics and heat transfer (Devenport \& Schetz, 1998; Zheng \& Keith, 2003; Rozza et al., 2009). Some work in developing an educational user-friendly CFD interface and package has already been carried out (Pieritz et al., 2004) where the general aspects and simplification of the three main processes of CFD, the preprocessor, the solver and the post-processor were carefully considered. An electronic learning system while using an existing CFD package (Hung et al., 2005), and, integration of CFD with experimentation in the area of flow control research (Ardag et al., 2009) have been reported.

\subsection{CFD in engineering practice}

Why should CFD be included in an undergraduate fluid mechanics curriculum? The simple answer is that CFD has now a major component of professional life in engineering 
practice and to prepare students properly they must get exposure to all aspects of their chosen profession. In the areas of analysis and design, simulation based design is commonly used instead of the traditional "build and test", as it is much more cost effective than EFD and a substantial database is provided for diagnosing the adjacent flow field. Simulations can readily be done of physical flow phenomena that are difficult to measure, for example, full scale situations, environmental effects and hazards. With the introduction of CFD into a curriculum, it is possible to educate the young engineer as to the pros and cons of using the three areas, AFD, EFD and CFD and to be in a position to know which area to use according to the problem or project confronting them. Importantly, the engineer should learn not be prejudiced against using any of the three areas. So there is an increasing need to integrate computer-assisted learning and simulation, in the guise of CFD, into undergraduate engineering courses, both as a learning tool and as initial professional training.

\subsection{General concerns about introducing simulation into a curriculum}

Issues of concern arise when simulation is being introduced into a curriculum. These include learning vs. research objectives, usability vs. predetermined objectives and student demographics (Stern et al., 2006). A proper balance should be sought between these competing objectives, for example, it is just as important that a student be taught the practical and systematic ways of using a CFD package in a general sense, as well as achieving a specific result. There is much evidence from previous studies that: the use of simulation enhances the curriculum (Feisel \& Rosa, 2002; Rozza et al., 2009); there is increased learning efficiency and understanding (Keller et al., 2007; Kelsey, 2001; LaRoche et al., 2002); there is effectiveness of new and hands-on learning methods (Patil et al., 2009); and, it is effective to use a combination of physical and simulation laboratories (Stern et al., 2006). Importantly, userfriendly interfaces must be designed so that students do not struggle with the mechanics of performing simulations to the detriment of understanding concepts. Also, when developing a curriculum which incorporates CFD, care must be taken to include flows of current interest while including diverse learning objectives. It must be remembered that CFD has become a widely used tool in fluids engineering covering many industries including Aerospace, Chemical Processing, Automotive, Hydraulics, Marine and Oil \& Gas, and, hence choices have to be made when developing a curriculum.

In engineering practice, a current pacing element is the lack of personnel capable of using CFD. Until quite recently, most engineers using CFD software in industry and research centres had completed post-graduate degrees where CFD courses were taught either formally or informally. Now, as CFD becomes more pervasive in engineering practice and engineers are expected to use CFD without post-graduate education, teaching CFD at the undergraduate has become more usual and necessary. An obvious advantage of integration of CFD software into an undergraduate lecture and laboratory course is that analytical and experimental results can be compared with CFD results. The teaching approach would be to use interactive exercises to compliment traditional fluid mechanics course, and some success has already been noted in the previously mentioned studies above. 


\subsection{Specific concerns about introducing CFD into a curriculum}

There are many issues, which if not carefully considered and implemented, can lead to teaching and learning difficulties. For example, which is best? - demonstration using CFD software, or allowing the students hands-on experience and the ability to investigate for themselves. Also, CFD could very well detract from a deeper knowledge of fluid mechanics, as, for example, boundary conditions, inlet conditions etc. are often built into the CFD package, and can be set without any real understanding. Students soon realize that they can get results, and reasonably plausible results, by mechanically following instructions, and not having much understanding of methodology and/or procedures. There is no doubt that when a student first uses CFD, a lot of new knowledge and required skills descends on them from many directions hence rendering to a steep learning curve. Without careful planning this curve can become overwhelming. Lastly, because CFD software is relatively less expensive than laboratory equipment there is a danger that it may replace laboratory experiments when this is not appropriate.

The questions in the above paragraph need to be assessed and evaluated when developing a curriculum. Here, the emphasis is on the development, implementation and evaluation of an effective curriculum for students to learn CFD, keeping in mind the issues of the previous paragraph, as part of a fluid mechanics course at intermediate undergraduate level. The objectives are to supplement and enhance the traditional course and to prepare students to use CFD effectively in engineering practice. The software chosen here is a commercial industrial software, and exposes students to the same or similar software they may use as professionals in industry. The software package provides students with a "Virtual Reality" interface, which allows for relative ease in setting up flows and the ability to visually reinforce concepts in fluid flow and heat transfer during the post-processor stage.

\subsection{Outline of the chapter}

In Section 2 of this chapter, basic computational fluid dynamics elements introduced to students in two lectures at the start of their course to introduce CFD elementary theory, methodology and procedures are outlined. In Section 3 the concept of the CFD interface is explained and in Section 4 the course/laboratories, learning objectives, applications, coursework and the integration of the CFD laboratories into the existing fluid mechanics course are described. Section 5 presents evaluation design, results and discussion, in the form of three investigations, one as a controlled experiment comparing the CFD group with a controlled group, one measuring the student learned knowledge and skills regarding the CFD interface and one eliciting student views on using CFD by questionnaire. Section 6 gives conclusions drawn and possible work for the future.

\section{Basic computational fluid dynamics elements}

This section outlines essential elementary CFD theory, which must be introduced students before they encounter hands-on experience in the laboratory. The following are extracts from the initial lectures given to the CFD student group. 


\subsection{Overall idea of CFD}

CFD is used to replace the continuous problem domain with a discrete domain using a grid. In the continuous domain, each flow variable is defined at every point in the domain, whereas in the discrete domain, each flow variable is defined only at the grid nodes or subgrid nodes. In a CFD solution, the relevant flow variables would only be directly solved at the grid nodes with values between obtained by interpolation. The governing partial differential equations and boundary conditions are defined in terms of the continuous variables, velocity, pressure, etc. These can be approximated in the discrete domain leading to a large set of coupled, algebraic equations in the discrete variables. Setting up this discrete system, and solving it involves a large number of repetitive calculations, hence the use of computers.

\subsection{Discretization using the finite-volume method}

To keep the explanation simple, consider the following 1D equation.

$$
\frac{\mathrm{du}}{\mathrm{dx}}+\mathrm{u}=0 ; \quad 0 \leq \mathrm{x} \leq 1 ; \quad \mathrm{u}(0)=1
$$

A typical discrete representation of the above equation is shown on the following grid,

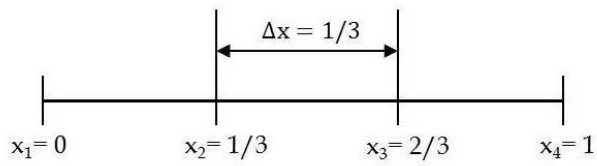

Figure 1. Discrete representation

This grid has four equally spaced grid nodes with $\Delta x$ being the spacing between successive nodes, and since the governing equation is valid at any grid node then,

$$
\left(\frac{d u}{d x}\right)_{i}+u_{i}=0
$$

where the subscript $\mathrm{i}$ represents the value at grid node $\mathrm{x}_{\mathrm{i}}$. In order to get an expression for $(\mathrm{du} / \mathrm{dx})_{\mathrm{i}}$ in terms of $\mathrm{u}$ at the grid nodes, $\mathrm{u}_{\mathrm{i}-1}$ is expanded in a Taylor's series,

$$
\mathrm{u}_{\mathrm{i}-1}=\mathrm{u}_{\mathrm{i}}-\Delta \mathrm{x}\left(\frac{\mathrm{du}}{\mathrm{dx}}\right)_{\mathrm{i}}+\mathrm{O}\left(\Delta \mathrm{x}^{2}\right)
$$

The error in $(\mathrm{du} / \mathrm{dx})_{\mathrm{i}}$ due to neglecting terms in the Taylor series is called the truncation error, and, since the truncation error is $\mathrm{O}(\Delta \mathrm{x})$ this discrete representation is termed firstorder accurate.

The following discrete equation then ensues,

$$
\frac{u_{i}-u_{i-1}}{\Delta x}+u_{i}=0
$$

which is an algebraic equation. 
When dealing with two-dimensional geometry the grid used in the CFD laboratories here will consist of relatively simple rectangles, or a Cartesian grid. In the finite-volume method, such a rectangle is called a "cell". For 2D flows, triangular cells are often used. For the 3D flows used in the laboratories here the grid will have cuboid cells. It should be noted that it is also common to use hexahedrals, tetrahedrals or prisms. In the finite-volume approach, the integral form of the conservation equations is applied to the control volume defined by a cell to get the discrete equations for the cell. The integral form of the continuity equation for steady, incompressible flow is shown below, where the integration is over the surface $S$ of the control volume and $\vec{n}$ is the outward normal at the surface. This really means from this equation that the net volume flow into the control volume is zero.

$$
\int_{S} \vec{V} \cdot \vec{n} d S=0
$$

Consider the rectangular cell shown,

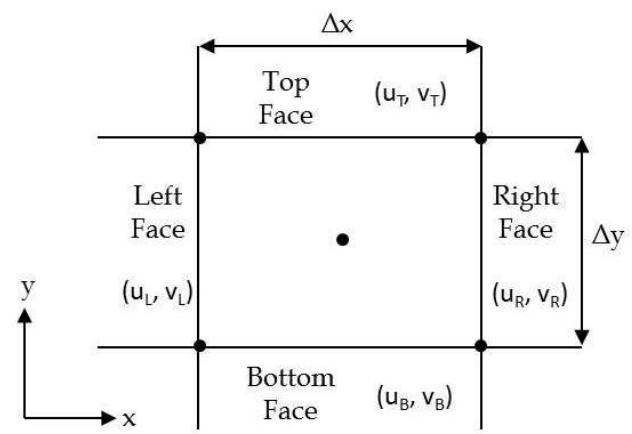

Figure 2. Cartesian control volume

The velocity at face $i$ is taken to be $\vec{V}_{i}=u_{i} \hat{\imath}+v_{i} \hat{\jmath}$. Applying the mass conservation Equation (5) to the control volume defined by the cell gives,

$$
-\mathrm{u}_{\mathrm{L}} \Delta \mathrm{y}-\mathrm{v}_{\mathrm{B}} \Delta \mathrm{x}+\mathrm{u}_{\mathrm{R}} \Delta \mathrm{y}+\mathrm{v}_{\mathrm{T}} \Delta \mathrm{x}=0
$$

This is the discrete form of the continuity equation for the cell. It is equivalent to summing up the net mass flow into the control volume and setting it to zero. Discrete equations for the conservation of momentum and energy for the cell can also be obtained.

Rearranging Equation (4) gives,

$$
-\mathrm{u}_{\mathrm{i}-1}+(1+\Delta \mathrm{x}) \mathrm{u}_{\mathrm{i}}=0
$$

Applying this equation to the 1D grid (Fig. 1) shown earlier at grid points $i=2,3,4$ gives,

$$
\left[\begin{array}{cccc}
-1 & 1+\Delta \mathrm{x} & 0 & 0 \\
0 & -1 & 1+\Delta \mathrm{x} & 0 \\
0 & 0 & -1 & 1+\Delta \mathrm{x}
\end{array}\right]\left[\begin{array}{l}
\mathrm{u}_{2} \\
\mathrm{u}_{3} \\
\mathrm{u}_{4}
\end{array}\right]=\left[\begin{array}{l}
0 \\
0 \\
0
\end{array}\right]
$$


The discrete equation cannot be applied at the left boundary $(\mathrm{i}=1)$ since $\mathrm{u}_{\mathrm{i}-1}$ is not defined. Instead, a boundary condition must be applied here.

In a general situation, the discrete equations are applied for the cells in the interior of the domain. For grid cells at or near the boundary, a combination of discrete equations and boundary equations are applied. This leads to a system of simultaneous algebraic equations. Boundary conditions are very important to have a well-defined problem and it should be remembered that a wrong boundary condition will give a totally wrong result.

In a practical CFD application, depending on the size of the grid and the number of variables to be solved for, the number of unknowns in a discrete system may run into thousands or even millions so the matrix inversion needed to solve the system of equations needs to optimized. Also due to the truncation error of Equation (3), it is clear that as the number of grid points is increased, and $\Delta \mathrm{x}$ is reduced, the error in the numerical solution would decrease and the agreement between numerical and exact solutions would be better. When the numerical solutions obtained on different grids agree to within a level of tolerance specified by the user, they are referred to as "grid converged" solutions. The concept of grid convergence applies to the finite-volume approach also when the numerical solution, if correct, becomes independent of the grid as the cell size is reduced. It is very important that the effect of grid resolution on the solution is always investigated.

\subsection{Basic equations of CFD}

The Navier-Stokes and continuity equations provide the foundations for modelling fluid motion. The laws of motion that apply to solids are valid for all matter including liquids and gases. A principal difference, however, between fluids and solids is that fluids distort without limits. Analysis of a fluid needs to take account of such distortions. The Navier-Stokes equations can be derived by considering the dynamic equilibrium of a fluid element. They state that the inertial forces acting on a fluid element are balanced by the surface and body forces. For incompressible flow, that is when the fluid density is constant, and ignoring body forces, the Navier-Stokes equations can be written as,

$$
\begin{gathered}
\frac{\partial u}{\partial x}+\frac{\partial v}{\partial y}+\frac{\partial w}{\partial z}=0 \\
\rho\left(\frac{\partial u}{\partial t}+u \frac{\partial u}{\partial x}+v \frac{\partial u}{\partial y}+w \frac{\partial u}{\partial z}\right)=-\frac{\partial p}{\partial x}+\mu\left(\frac{\partial^{2} u}{\partial x^{2}}+\frac{\partial^{2} u}{\partial y^{2}}+\frac{\partial^{2} u}{\partial z^{2}}\right) \\
\rho\left(\frac{\partial v}{\partial t}+u \frac{\partial v}{\partial x}+v \frac{\partial v}{\partial y}+w \frac{\partial v}{\partial z}\right)=-\frac{\partial p}{\partial y}+\mu\left(\frac{\partial^{2} v}{\partial x^{2}}+\frac{\partial^{2} v}{\partial y^{2}}+\frac{\partial^{2} v}{\partial z^{2}}\right) \\
\rho\left(\frac{\partial w}{\partial t}+u \frac{\partial w}{\partial x}+v \frac{\partial w}{\partial y}+w \frac{\partial w}{\partial z}\right)=-\frac{\partial p}{\partial z}+\mu\left(\frac{\partial^{2} w}{\partial x^{2}}+\frac{\partial^{2} w}{\partial y^{2}}+\frac{\partial^{2} w}{\partial z^{2}}\right)
\end{gathered}
$$

In the above equations, $\mathrm{u}, \mathrm{v}, \mathrm{w}$ are the velocity components in the $\mathrm{x}, \mathrm{y}, \mathrm{z}$ directions, $\rho$ is the density, $\mathrm{p}$ is the pressure, and $\mu$ is the viscosity.

Turbulence is of fundamental interest to engineers because most flows encountered in engineering are turbulent. This happens because it is difficult to keep the flow laminar, or by 
intention as turbulence is essential for the engineering application. However, for turbulent flows, the variation of quantities with time is so random that its detailed variation can be of little, if any, engineering relevance so averaged quantities with time are therefore calculated using the Reynolds-averaged Navier-Stokes equations shown below.

$$
\begin{gathered}
\frac{\partial \overline{\mathrm{u}}}{\partial \mathrm{x}}+\frac{\partial \overline{\mathrm{v}}}{\partial \mathrm{y}}+\frac{\partial \overline{\mathrm{w}}}{\partial \mathrm{z}}=0 \\
\rho\left(\frac{\partial \overline{\mathrm{u}}}{\partial \mathrm{t}}+\overline{\mathrm{u}} \frac{\partial \overline{\mathrm{u}}}{\partial \mathrm{x}}+\overline{\mathrm{v}} \frac{\partial \overline{\mathrm{u}}}{\partial \mathrm{y}}+\overline{\mathrm{w}} \frac{\partial \bar{u}}{\partial z}\right)=-\frac{\partial \overline{\mathrm{p}}}{\partial \mathrm{x}}+\frac{\partial}{\partial \mathrm{x}}\left(\mu \frac{\partial \overline{\mathrm{u}}}{\partial \mathrm{x}}-\rho \overline{\mathrm{u}^{\prime} \mathrm{u}^{\prime}}\right) \\
+\frac{\partial}{\partial \mathrm{y}}\left(\mu \frac{\partial \overline{\mathrm{u}}}{\partial \mathrm{y}}-\rho \overline{\mathrm{u}^{\prime} \mathrm{v}^{\prime}}\right)+\frac{\partial}{\partial \mathrm{z}}\left(\mu \frac{\partial \overline{\mathrm{u}}}{\partial \mathrm{z}}-\rho \overline{\mathrm{u}^{\prime} \mathrm{w}^{\prime}}\right) \\
\rho\left(\frac{\partial \overline{\mathrm{v}}}{\partial \mathrm{t}}+\overline{\mathrm{u}} \frac{\partial \overline{\mathrm{v}}}{\partial \mathrm{x}}+\overline{\mathrm{v}} \frac{\partial \overline{\mathrm{v}}}{\partial \mathrm{y}}+\overline{\mathrm{w}} \frac{\partial \bar{v}}{\partial z}\right)=-\frac{\partial \overline{\mathrm{p}}}{\partial \mathrm{y}}+\frac{\partial}{\partial \mathrm{x}}\left(\mu \frac{\partial \overline{\mathrm{v}}}{\partial \mathrm{x}}-\rho \overline{\mathrm{u}^{\prime} \mathrm{v}^{\prime}}\right) \\
+\frac{\partial}{\partial \mathrm{y}}\left(\mu \frac{\partial \overline{\mathrm{v}}}{\partial \mathrm{y}}-\rho \overline{\bar{v}^{\prime} \mathrm{v}^{\prime}}\right)+\frac{\partial}{\partial \mathrm{z}}\left(\mu \frac{\partial \overline{\mathrm{v}}}{\partial \mathrm{z}}-\rho \overline{\mathrm{v}^{\prime} \mathrm{w}^{\prime}}\right) \\
\rho\left(\frac{\partial \overline{\mathrm{w}}}{\partial \mathrm{t}}+\overline{\mathrm{u}} \frac{\partial \overline{\mathrm{w}}}{\partial \mathrm{x}}+\overline{\mathrm{v}} \frac{\partial \overline{\mathrm{w}}}{\partial \mathrm{y}}+\overline{\mathrm{w}} \frac{\partial \bar{w}}{\partial z}\right)=-\frac{\partial \overline{\mathrm{p}}}{\partial \mathrm{z}}+\frac{\partial}{\partial \mathrm{x}}\left(\mu \frac{\partial \overline{\mathrm{w}}}{\partial \mathrm{x}}-\rho \overline{\mathrm{u}^{\prime} \mathrm{w}^{\prime}}\right) \\
+\frac{\partial}{\partial \mathrm{y}}\left(\mu \frac{\partial \overline{\mathrm{w}}}{\partial \mathrm{y}}-\rho \overline{\mathrm{v}^{\prime} \mathrm{w}^{\prime}}\right)+\frac{\partial}{\partial \mathrm{z}}\left(\mu \frac{\partial \overline{\mathrm{w}}}{\partial \mathrm{z}}-\rho \overline{\mathrm{w}^{\prime} \mathrm{w}^{\prime}}\right)
\end{gathered}
$$

All the instantaneous quantities were replaced by their corresponding time-averaged quantities. Also, due to the averaging process extra terms appear, for example, $-\rho \overline{u^{\prime} u^{\prime}}, \rho \overline{u^{\prime} w^{\prime}}$ appear. These terms behave like stress terms and require further equations if the system is to be solved. This will be further discussed in Section 2.6 (Turbulence Modelling) below.

\subsection{Boundary conditions}

When solving the Reynolds-averaged Navier-Stokes equations and continuity equation, appropriate initial conditions and boundary conditions need to be applied. Boundary conditions are a required component of the mathematical model and direct the motion of the flow. They can be used to specify fluxes into the computational domain, with boundaries and internal surfaces represented by face zones and boundary data assigned to these zones.

Different types of boundary conditions can be applied at surfaces. When using a Dirichlet boundary condition, one prescribes the value of a variable at the boundary, e.g. $u(x)=$ constant and when using a Neumann boundary condition, one prescribes the gradient normal to the boundary of a variable at the boundary, e.g. $\frac{\partial \mathrm{u}(\mathrm{x})}{\partial \mathrm{n}}=$ constant. It should be noted that at a given boundary, different types of boundary conditions can be used for different variables.

A wide range of boundary conditions types permit the flow to enter and exit the solution domain, for example, general (pressure inlet, pressure outlet), incompressible flow (velocity inlet, outflow), compressible flow (mass flow inlet, pressure far-field), and special (inlet vent, outlet vent, intake fan, exhaust fan). The boundary location and shape should be selected such that flow either goes in or out. This is not mandatory, but will typically result 
in better convergence. There should not be large gradients of variables in the normal direction to the boundary near inlets and outlets as this indicates an incorrect problem specification. Also grid skewness near a boundary should be minimized.

\subsection{Basic numerical solvers}

In a practical problem, as mentioned above, a matrix would be extremely large, so needing a prohibitively large amount of memory to invert it directly. Therefore the matrix would be inverted using an iterative scheme instead. Iteration serves two purposes, namely, it allows for efficient matrix inversion with greatly reduced memory requirements and it is necessary to solve nonlinear equations. In steady problems, a common and effective strategy used in CFD codes is to solve the unsteady form of the governing equations and march the solution in time until the solution converges to a steady value. In this case, each time step is effectively an iteration, with the guess value at any time level being given by the solution at the previous time level. The finite-difference equation at a grid point is arranged so that the quantity to be calculated is expressed in terms of values at the neighbouring grid points, including guessed values. Then as we sweep from say left to right on the grid, successive values of the variable are updated, including any guessed values. However, since guessed values at some of the neighbouring points were used, only an approximate solution for the matrix inversion during each iteration is obtained. However as each iteration ensues across the grid, the values of the variable at each grid point converges towards the exact solution, making the error introduced due to guessing tend to zero. This iterative type of matrix inversion allows for efficient matrix inversion with greatly reduced memory requirements and it is necessary when solving nonlinear equations.

How do we judge when the solution is converged. Basically it is when the difference between the value of the variable being solved at the present iteration step and it's value solved for in the previous iteration step, referred to as the residual, is small enough. It is very common to use the summation of the residuals at each grid point normalised by the average of the variable.

\subsection{Turbulence modelling}

There are two different states of flow, laminar and turbulent. Laminar flows are characterized by smoothly varying velocity fields in space and time and these flows arise when the fluid viscosity is sufficiently large to damp out any perturbations to the flow that may occur due to boundary imperfections or other irregularities. These flows occur at lowto-moderate values of the Reynolds number. Turbulent flows, on the other hand, are characterized by large, nearly random instabilities that grow until nonlinear interactions cause them to break down into finer and finer eddies that eventually are dissipated by the action of viscosity.

For turbulent flow there is a deviation of the velocity from the mean value defined as, 


$$
\mathrm{u}^{\prime} \equiv \mathrm{u}-\overline{\mathrm{u}}
$$

Due to this deviation, or more commonly called the fluctuation in velocity, and when the Navier-Stokes equations are averaged to become the Reynolds-Averaged Navier-Stokes equations, which are the equations which govern the mean velocity and pressure in the CFD package used here, extra terms are introduced called Reynolds stresses. This presents a problem in that there are more unknowns than there are equations leading to the necessity to model these extra terms to "close" the equations. There have over this last 50-60 years been many ways suggested as the best solution for closure, none of which are completely satisfactory. For the CFD laboratories here, the k- $\varepsilon$ and the LVEL (Agonafer et al., 2008; Launder \& Spalding, 1972) methods will be used.

\section{Computational fluid dynamics teaching laboratories}

\subsection{Introduction}

For the CFD laboratories the interface is a "three-dimensional" fully interactive environment. This interface uses, "virtual reality", is easy-to-use, and allows a student to simulate a flow from beginning to end without resorting to specialized codes. The code is also used widely in the professional engineering, so giving students useful skills which contribute to their preparation for the workplace. The virtual reality environment is designed as a general purpose CFD interface consisting of the VR-Editor (pre-processor), the VR-Viewer (post-processor) and the solver module which performs the flow simulation calculations. The VR-Editor allows the student to set the size of the computational domain, define the position, size and properties of objects to be introduced into the domain, specify the material(s) which occupies the domain, specify the inlet and outlet boundary conditions, specify the initial conditions, select a turbulence model when necessary, specify the position and fineness of the computational grid, and specify other parameters influencing the speed of convergence of the solution procedure. On setting up a particular flow, the characteristics of the flow are calculated using the solver module. The progress of the calculations is clearly monitored until convergence is reached or the iteration limit is reached. In the VRViewer, the results of a flow simulation are displayed graphically. The post-processing capabilities of the VR-Viewer used here are, vector plots, contour plots, iso-surfaces, streamlines and $\mathrm{x}-\mathrm{y}$ plots.

\subsection{Interface design specifications}

The CFD laboratory is designed so that practical procedures are user-friendly and easy to implement, and also to show students that CFD methodology needs to be systematic and rigorous. The complete process, at this level of CFD can, if so desired, be completely automated with the students going through a step-by-step process seamlessly from the set-up of the problem, through the solving to the display of the results. However it is very important that the laboratory also mirrors what is found in engineering practice, where a systematic approach is found. Careful consideration must be given to the areas listed in Table 1 below. 


\begin{tabular}{|l|l|}
\hline Geometry & Solid and other fluid boundaries \\
\hline Physics & $\begin{array}{l}\text { Incompressible/compressible fluid, } \\
\text { which quantities to be solved for, } \\
\text { closure of the equations, initial and } \\
\text { boundary conditions }\end{array}$ \\
\hline Grid & $\begin{array}{l}\text { The choice here is Cartesian meshing or } \\
\text { orthogonal meshing. The Cartesian } \\
\text { mesh can be automatically generated or } \\
\text { built manually. }\end{array}$ \\
\hline Numerics & $\begin{array}{l}\text { Convergence monitoring, selection of } \\
\text { numerical scheme. }\end{array}$ \\
\hline Post-processing & $\begin{array}{l}\text { Flow visualization, analysis, } \\
\text { verification, validation using published } \\
\text { experimental or empirical data. }\end{array}$ \\
\hline
\end{tabular}

Table 1. Areas for systematic consideration

To contribute to the student's self-learning, a hierarchical system of predefined active options within the virtual reality environment are introduced for later simulations.

\subsection{Interface design features}

The design of the CFD interface (shown on Fig. 3) was chosen and designed to have features which systematically informs, is vocationally sound and is easy to use.

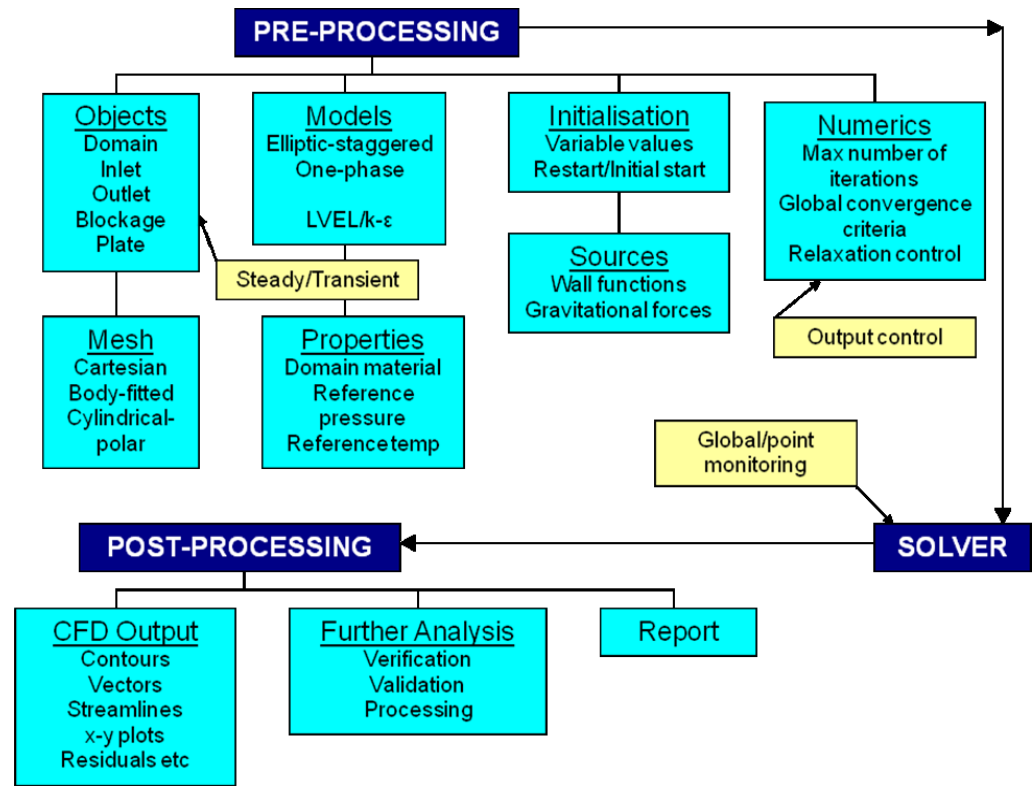

Figure 3. Summary of CFD interface 
Each simulation process follows exactly how modelling is carried out in engineering practice, with the students setting up, solving and analysing the particular problem step-bystep.

The students interact with the software using mouse and keyboard input. There was no requirement for advanced computer language skills enabling the students to concentrate on the methodology and procedures of CFD. An important feature of the CFD interface is that it is stand-alone. By this is meant that grid generation, solving and post-processing are all combined in the virtual reality environment.

Also important is that the results obtained by students could be easily moved to Microsoft Office during the reporting stage. As the software package is built on the Windows OS using PCs with relatively low computer power, it was important that the CFD interface was built on fast and accurate solvers, as is found for this software. Because students are given a limited time in the laboratory, and also in order to keep their level of interest heightened, results should come back reasonably quickly. The post-processor was designed to plot contours, vectors, streamlines and, when needed, to make animations. Students had access to colour printers to produce figures for their reports.

\section{Integration of CFD laboratory into fluid mechanics curriculum}

\subsection{Existing fluid mechanics undergraduate course}

The CFD laboratory was integrated into a fourth semester course, for students of mechanical engineering. Traditionally the course used two lectures, each 3 hours in length, per week for theoretical fluid mechanics with four experimental laboratories, from Week 3 to Week 10, giving hands-on experience and demonstration of fundamental principles over the twelve week semester. The laboratories were given 3 hours per week to complete. With the introduction of CFD, the course was restructured to consist of two lectures, each three hours per week for theoretical mechanics, and, two CFD laboratories and two experimental laboratories. Again these laboratories were from Week 3 to Week 10, and the CFD laboratories alternated with the experimental laboratories. Two textbooks were also added to the required reading list (Ferziger \& Peric, 1996; Tu et al., 2007).

The main learning outcomes are to understand the equations that govern fluid flow (conservation of mass, momentum and energy) and be able to apply them to a range of practical problems, including:

- $\quad$ predicting drag forces on bluff, streamline bodies and flat plates;

- $\quad$ analysing the flow in pipe systems;

- $\quad$ analysing performance of radial flow pumps and turbines; and,

- matching pumps and turbines for particular applications.

The unit also aims to develop skills in working effectively with others through the laboratory component of the unit. One or two seminars were help early in the semester, to discuss expectations regarding laboratory practice and reporting. The CFD student group was initiated to CFD as discussed next. 


\subsection{Necessary initiation of students to CFD}

With the introduction of CFD into the course two extra lectures, each 2 hours in length, entitled "An Introduction to Computational Fluid Dynamics (CFD)" were presented to prepare students to learn CFD methodology and procedures.

\subsubsection{Complementary nature of CFD and experimental fluid mechanics}

During the first lecture, the students are introduced to the idea that theoretical fluid mechanics, experimental fluid mechanics and computational fluid dynamics are complementary in modern engineering practice. As with the experimental laboratories, students are then introduced to CFD general methodology and procedures. The students learn as to when and why CFD is used, and the breakdown of CFD into three processes namely the pre-processor, the solver and the post-processor. This is followed by the idea of a finite domain, subdividing the domain into control volumes (Cartesian grid), selecting the quantities to be calculated (and hence which conservation equations to be used), geometrical aspects, fluid and solid properties, sources within the domain (e.g. gravitational force), some of the numerical details (including initialization, the iterative process and how to achieve convergence), the use of different boundary conditions (solid wall, inlet, outlet), and finally how to close the conservation equations using turbulence modelling (k- $\varepsilon$, LVEL) (Agonafer et al., 2008; Launder \& Spalding, 1972). Lastly, and importantly, the students are taught to be critical of their results and how to examine if what they are getting is what they might have expected.

\subsubsection{CFD methodology and procedures}

In the second lecture, the important part is a demonstration with full facilities for students to have 'hands-on' experience as the demonstration proceeds. Several simple threedimensional flows are used as exemplars to give an overall view of the CFD process. The virtual reality environment, (Fig. 4), which facilitates the VR-Editor (pre-processor), the VRViewer (post-processor) and the solver module, which performs the simulation calculations, is introduced.

It is demonstrated how the VR-Editor is used to set the size of the computational domain, defining the position, size and properties of objects introduced into the domain, specifying the material which occupies the domain, specifying inlet and outlet boundary conditions, specifying initial conditions, selecting a turbulence model (if appropriate), specifying the fineness of the computational grid and setting parameters which influence the speed of convergence of the solution procedure. Viewing movement controls are also introduced for zooming, rotation, and, vertical and horizontal translations. It is then shown how to create a new simulation and to set data for geometry, automatic meshing, the quantities to be solved and the turbulence model. Objects are introduced as required together with any inlets and outlets. Finally the solver parameters are specified for the total number of iterations, the position of a 
'probe', partially needed for monitoring convergence as the solver proceeds, is set, and the students are encouraged to have a final look at the automatic mesh and positions of objects before starting to solve.

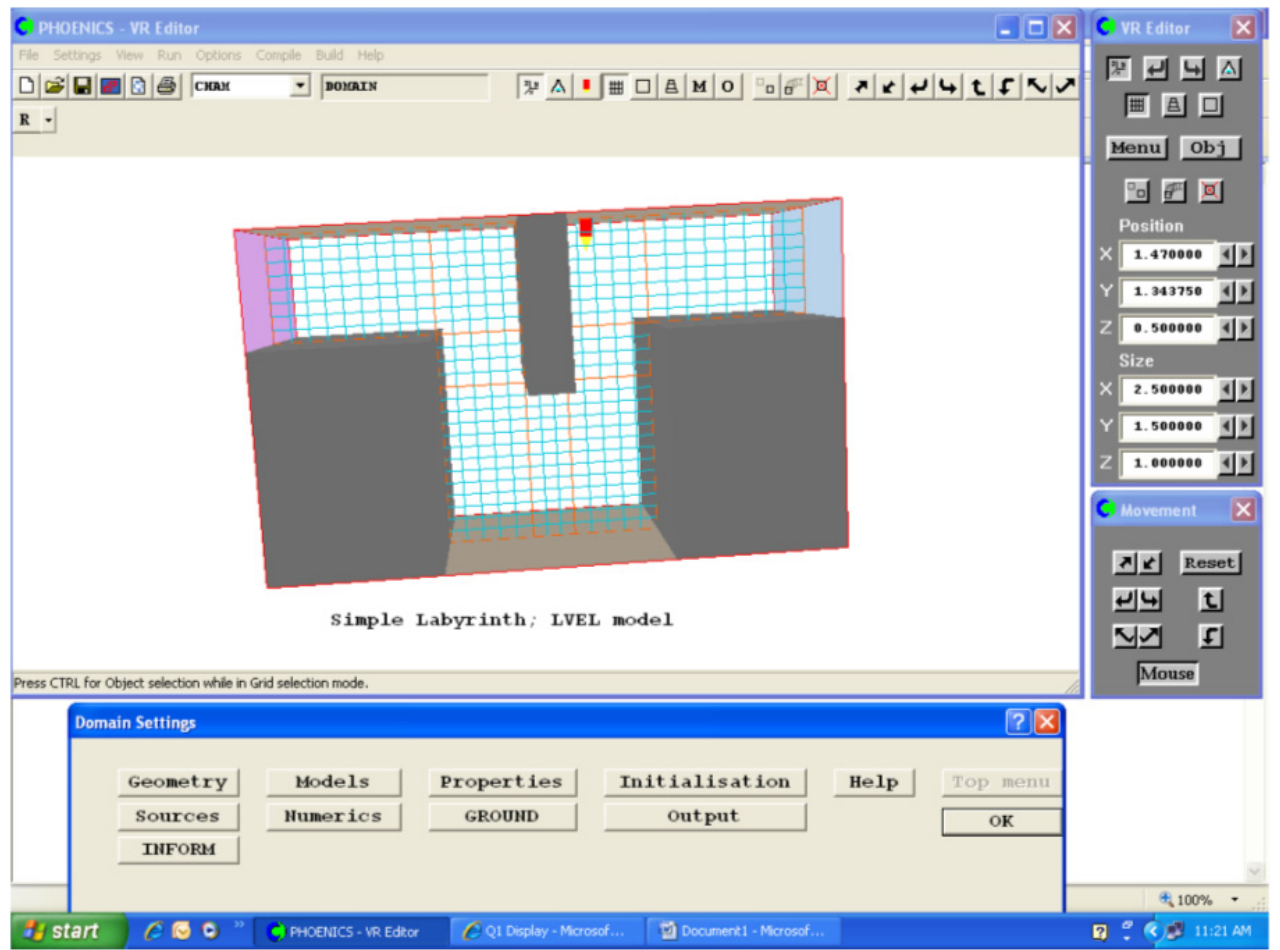

Figure 4. General view of VR-Editor (pre-processor)

As a converged solution is approached, the variables at the monitoring point become constant while with each successive sweep through the domain, the values of the errors are shown to decrease steadily.

On completion of the solver, the results of the flow-simulation can be viewed using the post-processor called the VR-Editor. This can display vector plots, contour plots, isosurfaces, streamlines and $x-y$ plots as demonstrated on Fig. 5. For ease of use the VRViewer is close to the design of the VR-Editor but with clearly marked toggle-buttons for vector display, etc. 


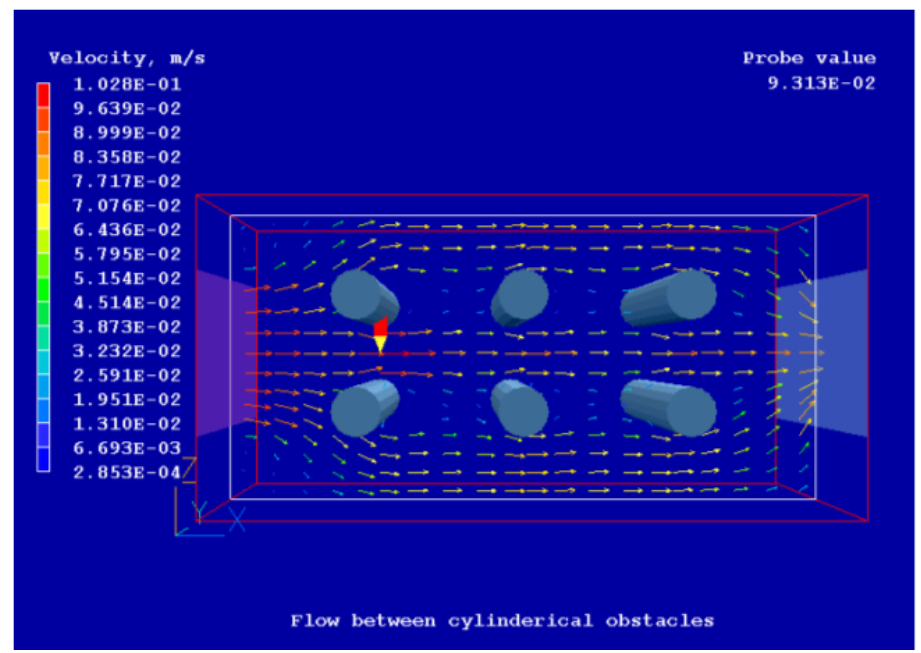

Figure 5. Typical vector-plot output of the post-processor

The students are encouraged to display the quantities calculated in various ways and also to experiment with each of the control buttons for zooming, rotating and obtaining meaningful views of selected planes. The students are shown how to print their results and save both input and output files. A second example is then demonstrated where instead of using the automated mesh option, students are taught to think why and where fine and coarse meshing is appropriate and how to implement it. Also included is how to produce $x-y$ plots, an important part of assignment work, and reporting system in professional life.

This lecture concludes with a broader look at CFD, including a more in-depth look at numerical methods in CFD, turbulence modelling for CFD and grid-generation alternatives to the Cartesian grid.

\subsection{Replacing laboratory experiments with CFD simulation}

From the original four experimental laboratories, "Predicting drag forces on bluff, streamline bodies and flat plates" and "Analysing the flow in pipe systems" were chosen to become CFD laboratories while "Analysing performance of radial flow pumps and turbines" and "Matching pumps and turbines for particular applications" remained as experimental. The four laboratories were conducted sequential from the beginning to the end of the semester. The students were expected to be self-guided to encourage self-learning for both the CFD and experimental laboratories, although a tutor and technician were in attendance. Detailed step-by-step notes were provided for all four laboratories.

To overcome some of the issues mentioned in the introduction concerning integration of CFD into the fluid mechanics course, it was decided to allow students, as much as possible, to have hands-on experience and investigations and assignments by themselves as opposed to demonstration. When setting boundary conditions, especially near-wall conditions, 
students had to explain such topics as the need for grid refinement, so getting them to think rather than just mechanically do. Also the students were encouraged to gradually develop a 'feeling' for when pressure or mean velocity gradients were high within the flow and hence generate higher mesh densities, so again getting away from a mechanical approach. The steep learning curve met during the early days of the course was partly alleviated by getting the students to stick strictly to the procedures of Fig. 3.

\section{Teaching and learning evaluation}

The evaluation process was subdivided into three investigations, one in the form of a controlled experiment comparing the knowledge of the group with CFD in their course with those of a controlled group using only the conventional experimental laboratories, the second measuring student knowledge and skill outcomes for the CFD interface, and, the third in the form of an online questionnaire eliciting the views of students on using CFD.

\subsection{Controlled experiment}

To investigate the effectiveness of introducing CFD laboratories into the fluid mechanics course, a controlled experiment applying a pre-test-post-test control group design was conducted (Pfahl et al., 2004). The students had to undertake two tests, one before the respective course (pre-test) and one after the respective course (post-test) with the introduction of CFD laboratories then being evaluated by comparing within-student posttest to pre-test scores, and by comparing the scores between students in the CFD group (A), i.e. those who were taught using the course containing CFD laboratories, to those students in the control group (B), i.e. taught using the conventional method of experimental laboratories only. The various possibilities of the methods of teaching the students are summarized using Fig. 6.

Level 1:

Learning Goal

Level 2:

Teaching \& Learning Method

Level 3:

Method attributes

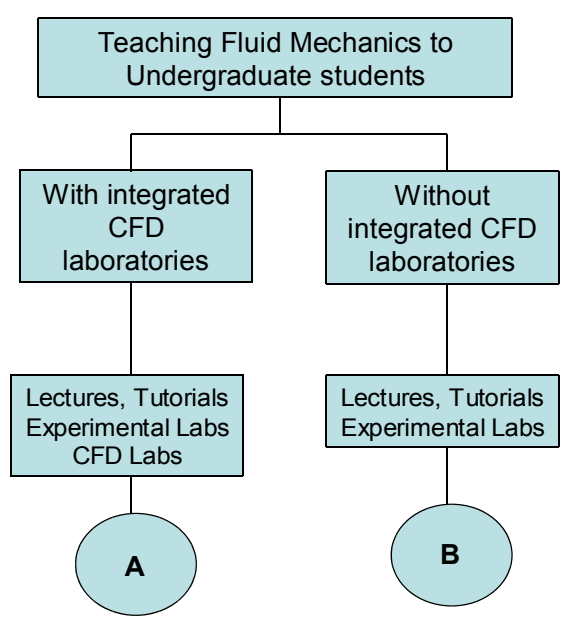

Figure 6. Course arrangements 
To measure the performance of the two groups, four constructs were used with each construct represented by one dependent variable. Each dependent variable has the hypothesis,

1. There is a positive learning effect in both groups (A: CFD group, B: control group). This means post-test scores are significantly higher than pre-test scores for each dependent variable.

2. The learning is more effective for group A than for group B, either with regard to the performance improvement between pre-test and post-test (the relative learning effect), or with regard to post-test performance (absolute learning effect). The absolute learning effect is of interest because it may indicate an upper bound of the possible correct answers depending on the method of teaching.

The design starts with random assignment of students to the CFD group (A) and control group (B) with the members of both groups completing a pre-test and post-test. The pre-test measured the performance of the two groups before the courses and the post-test measured the performance of the two groups after the courses. The students did not know that the post-test and pre-test questions were identical and neither were they allowed to retain the pre-test questions with the correct answers only given to the students after the experiment.

The students were in the fourth semester of an engineering course with the number of students in group $A, N_{A}=46$, and in group $B, N_{B}=35$. The personal characteristics of the students are summarized in Table 2.

\begin{tabular}{|l|l|}
\hline \multicolumn{2}{|l|}{ Characteristics } \\
\hline Average age & 22.3 years \\
Percentage female & $21 \%$ \\
Preferred learning style(s) & \\
Reading with exercise & $16 \%$ \\
Lecture & $11 \%$ \\
Tutorial & $30 \%$ \\
Laboratory & $18 \%$ \\
Working in groups (with peers) & $25 \%$ \\
Opinion of most effective learning style(s) & \\
Reading with exercise & $9 \%$ \\
Lecture & $10 \%$ \\
Tutorial & $32 \%$ \\
Laboratory & $18 \%$ \\
Working in groups & $31 \%$ \\
\hline
\end{tabular}

Table 2. Personal characteristics

The initial testing was conducted after a short introduction as to the purpose of the experiment and general organizational issues. The pre-test was then carried out with the data for the dependent variables collected. Following the pre-test, the students were placed 
in either the control group or the experimental group and all students participated in both the pre-test and post-test. After completing their courses, both groups of students performed the post-test using the same questions as during the pre-test, thus providing data on the dependent variables for the second time. In addition the students were asked to answer questions about subjective perceptions.

Dependent variables

J.1 Interest in Fluid Mechanics ('Interest')

J.2 General knowledge of Fluid Mechanics('Understand general')

J.3 Understanding of 'simple' Fluid Mechanics ('Understand simple')

J.4 Understanding of 'difficult' Fluid Mechanics ('Understanding difficult')

Subjective perceptions

S.1 Available time budget versus time need ('Time pressure')

S.2 Course evaluation (useful, engaging, easy, clear)

Table 3. Experimental variables

Data for two types of variables were collected, the dependent variables (J.1, .., J.4) and the subjective perception variables (S.1, S.2). These variables are listed in Table 3. The dependent variables are constructs used to capture aspects of learning provided by the courses and each was measured using 5 questions. Selected examples of questions used as shown in Table 4.

The results for the dependent variable J.1 were found by applying a five-point Likert-type scale (Likert, 1932) with each answer mapped to the value range $R=[0,1]$.

The values for variables J.2 - J.4 are average scores derived from five questions for each. Missing answers were marked as incorrect. The data for the subjective perception variables was collected after the post-test. The values for variable S.1 are normalized averages reflecting the time needed for understanding and doing the tasks associated with Weeks 2 12.

The descriptive statistics for the experiment are summarized in Table 5. The columns 'Pretest scores' and 'Post-test scores' show the calculated values for mean $(\overline{\mathrm{x}})$, median $(\mathrm{m})$ and standard deviation $(\sigma)$ of the raw data collected, and the column 'Difference scores' shows the difference between the post-test and pre-test scores. 
J.1 example question

I consider it very important for mechanical engineering students to know as much as possible about fluid mechanics. $(1=$ fully agree $/ 5$ = fully disagree $)$ Circle number below.

$\begin{array}{lllllll}\text { Agree } & 1 & 2 & 3 & 4 & 5 & \text { Disagree }\end{array}$

\section{J.2 example question}

What are the four main forces acting on an aircraft when flying straight and level?

J.3 example question

What is flow separation? What causes it? What is the effect of flow separation on the drag coefficient?

\section{J.4 example question}

Fluid flows out of a large tank into a straight section of pipe with a diameter d. A boundary layer of thickness $\delta$ grows along the pipe wall. Transition occurs at $x=0$ due to a sharp edge at the inlet. The turbulent boundary layer development may be approximated by the flat-plate relation, $\delta / x=0.391 \mathrm{Re}^{-}$ 0.2. Estimate the distance required for the boundary layer to completely fill the pipe for a Reynolds number of $2 \times 10^{5}$, neglecting changes in core velocity $U$ with $\mathrm{x}$.

S.1 example question

I did not have enough time to:

- complete the tutorials

- complete the laboratory sessions

- write-up the laboratory reports

- complete the post-test

S.2 example question

I consider the explanations/information provided for Laboratory Sessions

$\begin{array}{lllll}1 & 2 & 3 & 4 & 5\end{array}$

$\begin{array}{ll}\text { Useful } & \text { Useless } \\ \text { Boring } & \text { Engaging } \\ \text { Difficult } & \text { Easy } \\ \text { Clear } & \text { Confusing }\end{array}$

Table 4. Example questions (pre-test, post-test, subjective perceptions) 


\begin{tabular}{|l|l|l|l|l|l|l|l|l|l|l|l|l|l|}
\hline & \multicolumn{9}{|l|}{ Pre-test scores } & \multicolumn{3}{l|}{ Post-test scores } & \multicolumn{3}{l|}{ Difference scores } \\
\cline { 2 - 16 } & J.1 & J.2 & J.3 & J.4 & J.1 & J.2 & J.3 & J.4 & J.1 & J.2 & J.3 & J.4 \\
\hline Group A & & & & & & & & & & & & \\
$(\overline{\mathrm{x}})$ & 0.67 & 0.61 & 0.27 & 0.23 & 0.69 & 0.83 & 0.58 & 0.35 & 0.02 & 0.22 & 0.31 & 0.12 \\
$(\mathrm{~m})$ & 0.71 & 0.60 & 0.24 & 0.24 & 0.72 & 0.78 & 0.49 & 0.31 & 0.01 & 0.18 & 0.25 & 0.07 \\
$(\sigma)$ & 0.11 & 0.34 & 0.29 & 0.25 & 0.09 & 0.22 & 0.21 & 0.27 & 0.01 & 0.29 & 0.25 & 0.26 \\
\hline Group B & & & & & & & & & & & & \\
$(\bar{x})$ & 0.76 & 0.52 & 0.34 & 0.21 & 0.77 & 0.57 & 0.55 & 0.37 & 0.01 & 0.05 & 0.21 & 0.16 \\
$(\mathrm{~m})$ & 0.75 & 0.54 & 0.31 & 0.18 & 0.78 & 0.56 & 0.53 & 0.39 & 0.03 & 0.02 & 0.22 & 0.21 \\
$(\sigma)$ & 0.09 & 0.18 & 0.32 & 0.31 & 0.13 & 0.21 & 0.13 & 0.22 & 0.11 & 0.19 & 0.24 & 0.27 \\
\hline
\end{tabular}

Table 5. Scores of dependent variables

Table 6 shows the calculated values for mean, median and standard deviation of the raw data collected on subjective perceptions.

\begin{tabular}{|c|c|c|}
\hline & S.1 & S.2 \\
\hline Group A & & \\
$(\overline{\mathrm{x}})$ & 0.54 & 0.49 \\
$(\mathrm{~m})$ & 0.52 & 0.49 \\
$(\mathrm{\sigma})$ & 0.19 & 0.13 \\
\hline Group B & & \\
$(\overline{\mathrm{x}})$ & 0.46 & 0.48 \\
$(\mathrm{~m})$ & 0.41 & 0.44 \\
$(\mathrm{\sigma})$ & 0.21 & 0.14 \\
\hline
\end{tabular}

Table 6. Scores of subjective perceptions

The students in control group (B) expressed less need of additional time than those of the CFD group (A), while students of both groups were fairly equal in their perception of their respective course usefulness, engagement, difficulty and clarity.

Standard significance testing was used to investigate the effect of the treatments on the dependent variables J.1 to J.4. The null hypotheses were,

- $\quad \mathrm{H}_{0,1}$ : There is no difference between pre-test scores and post-test scores within experimental group (A) and control group (B).

- $\quad \mathrm{H}_{0,2 \mathrm{a}}$ : There is no difference in relative learning effectiveness between CFD group (A) and control group (B).

- $\quad \mathrm{H}_{0,2 \mathrm{~b}}$ : There is no difference in absolute learning effectiveness between CFD group (A) and control group (B).

For $\mathrm{H}_{0,1}$ and focusing on the CFD group (A), Table 7 shows the results using a one-tailed $\mathrm{t}$ test for dependent samples. Column one specifies the variable, column two represents the Cohen effect size, d, (Cohen, 1988; Ray \& Shadish, 1996), column three the degrees of freedom, column four the t-value of the study, column five the critical value for the significance value $\alpha=0.10$ and column six lists the associated p-value. 


\begin{tabular}{|c|c|c|c|c|c|}
\hline Variable & $\mathrm{d}$ & $\mathrm{df}$ & $\mathrm{t}$-Value & Crit.to.90 & $\mathrm{p}$-Value \\
\hline J.1 & 0.200 & 45 & 1.360 & 1.301 & 0.090 \\
\hline J.2 & 0.770 & 45 & 5.220 & 1.301 & 0.000 \\
\hline J.3 & 1.220 & 45 & 8.270 & 1.301 & 0.000 \\
\hline J.4 & 0.460 & 45 & 3.110 & 1.301 & 0.001 \\
\hline
\end{tabular}

Table 7. Results for 'post-test' versus 'pre-test' for group A

It can be seen from Table 7 that all dependent variables achieve a statistically and practically significant result.

Table 8 shows the results of testing hypothesis $\mathrm{H}_{0,1}$ for the control group (B) using a onetailed t-test for dependent samples. The structure of the table is the same as that of Table 7.

\begin{tabular}{|c|c|c|c|c|c|}
\hline Variable & $\mathrm{d}$ & $\mathrm{df}$ & $\mathrm{t}$-Value & Crit.to.90 & $\mathrm{p}$-Value \\
\hline $\mathrm{J} .1$ & 0.090 & 34 & 0.530 & 1.307 & 0.299 \\
\hline $\mathrm{J} .2$ & 0.260 & 34 & 1.540 & 1.307 & 0.066 \\
\hline $\mathrm{J} .3$ & 0.860 & 34 & 5.080 & 1.307 & 0.000 \\
\hline J.4 & 0.600 & 34 & 3.550 & 1.307 & 0.000 \\
\hline
\end{tabular}

Table 8. Results for 'post-test' versus 'pre-test' for group B

It can be seen from Table 8 that the control group (B) achieved statistically and practically significant results for dependent variables J.2 - J.4. For J.1 no significant results can be found.

For $\mathrm{H}_{0,2 \mathrm{a}}$ which states that the difference between post-test and pre-test scores of group $\mathrm{A}$ is not significantly larger than the one for group B. Table 9 shows for each dependent variable separately the results of testing hypothesis $\mathrm{H}_{0,2 \mathrm{a}}$ using a one-tailed $\mathrm{t}$-test for independent samples.

\begin{tabular}{|c|c|c|c|c|c|}
\hline Variable & $\mathrm{d}$ & $\mathrm{df}$ & $\mathrm{t}$-Value & Crit.to.90 & $\mathrm{p}$-Value \\
\hline J.1 & 0.130 & 79 & 1.160 & 1.292 & 0.125 \\
\hline J.2 & 0.690 & 79 & 6.130 & 1.292 & 0.000 \\
\hline J.3 & 0.410 & 79 & 3.640 & 1.292 & 0.000 \\
\hline J.4 & -0.150 & 79 & -1.330 & 1.292 & 0.906 \\
\hline
\end{tabular}

Table 9. Results for 'performance improvement' (Group A versus Group B)

It can be seen that the hypothesis $\mathrm{H}_{0,2 \mathrm{a}}$ can be rejected only for the variables J.2 and J.3. The value for J.4 indicates that the relative learning effect is superior when the students were exposed to experimental laboratories only.

Table 10 shows for each dependent variable separately the results of testing $\mathrm{H}_{0,2 \mathrm{~b}}$ using a one-tailed t-test for independent samples. 


\begin{tabular}{|c|c|c|c|c|c|}
\hline Variable & $\mathrm{d}$ & $\mathrm{df}$ & $\mathrm{t}$-Value & Crit.to.90 & $\mathrm{p}$-Value \\
\hline J.1 & -0.720 & 79 & -6.430 & 1.292 & 1.000 \\
\hline J.2 & 1.210 & 79 & 10.820 & 1.292 & 0.000 \\
\hline J.3 & 0.170 & 79 & 1.520 & 1.292 & 0.066 \\
\hline J.4 & -0.080 & 79 & -0.715 & 1.292 & 0.762 \\
\hline
\end{tabular}

Table 10. Results for 'post-test improvement' (Group A versus Group B)

Again the two variables which show statistically significant results are J.2 and J.3 and hence $\mathrm{H}_{0,2 \mathrm{~b}}$ can be rejected for these variables. The variables J.1 and J.4 indicated that more interest is found in the totally experimental course and these students also did better in the more difficult aspects of the course.

\subsection{Student knowledge and skill outcomes for the CFD interface}

An objective measure of student knowledge and skill outcomes for the CFD interface as applied to the fluid mechanics curriculum was devised. Some of the questions used in the test are shown in Table 11, with the questions directed only at students of CFD group (A).

This test was again run on a pre/post CFD studies basis, i.e. during the first week of the course students completed the pre-test and later in the semester, and after completing the CFD studies, the students completed the post-test. The most intuitive test of students' knowledge and skill outcomes is whether the post-test scores were significantly higher than those of the pre-test scores. Table 12 contains the results for the mean and variance, the number of students $(\mathrm{N})$ taking the test is also shown and the test contained 20 questions.

As can be seen from Table 12, students correctly answer about $36 \%$ prior to being instructed in CFD and about $80 \%$ average correct for the post-test.

This represents a considerable improvement and is statistically highly significant, i.e.

$$
\overline{\mathrm{x}}_{\text {post }}-\overline{\mathrm{x}}_{\text {pre }}=8.52 ; \quad \mathrm{t}(1,33)=15.3 ; \mathrm{p}<0.0001
$$

It can be seen that the effect is substantial between pre- and post-tests and therefore represents significant improvement in outcomes of the students' knowledge and skills of CFD knowledge and skills. The students, after a relatively brief exposure to and with limited practice of CFD have shown considerable growth in their understanding of CFD concepts, principles and applied problems. 


\begin{tabular}{|c|l|}
\hline $\begin{array}{c}\text { Question } \\
\text { No. }\end{array}$ & \multicolumn{1}{c|}{ Question } \\
\hline 1 & $\begin{array}{l}\text { For flow over a cylinder, what is the cause of the different results found for } \\
\text { CFD and in the experimental laboratory? } \\
\text { a. The difference is caused by the experimental laboratory uncertainties. } \\
\text { b. The difference is caused by the errors from numerical and } \\
\text { experimental laboratory uncertainties. } \\
\text { c. The difference is caused by the errors from numerical methods. } \\
\text { d. The difference is caused by the errors from numerical, modelling and } \\
\text { experimental laboratory uncertainties. }\end{array}$ \\
\hline 2 & $\begin{array}{l}\text { What is a typical CFD process? } \\
\text { a. Geometry } \rightarrow \text { Mesh } \rightarrow \text { Properties } \rightarrow \text { Models } \rightarrow \text { Initiation } \rightarrow \\
\text { Verification } \rightarrow \text { Sources } \rightarrow \text { Numerics } \rightarrow \text { Solver } \rightarrow \text { Post-processing } \\
\text { b. Mesh } \rightarrow \text { Geometry } \rightarrow \text { Properties } \rightarrow \text { Models } \rightarrow \text { Initiation } \rightarrow \text { Sources } \\
\rightarrow \text { Numerics } \rightarrow \text { Solver } \rightarrow \text { Post-processing } \rightarrow \text { Verification } \\
\text { c. Geometry } \rightarrow \text { Mesh } \rightarrow \text { Properties } \rightarrow \text { Models } \rightarrow \text { Initiation } \rightarrow \text { Sources } \\
\rightarrow \text { Numerics } \rightarrow \text { Solver } \rightarrow \text { Post-processing } \rightarrow \text { Verification } \\
\text { d. Geometry } \rightarrow \text { Models } \rightarrow \text { Mesh } \rightarrow \text { Properties } \rightarrow \text { Initiation } \rightarrow \text { Sources } \\
\rightarrow \text { Numerics } \rightarrow \text { Solver } \rightarrow \text { Post-processing } \rightarrow \text { Verification }\end{array}$ \\
\hline 3 & $\begin{array}{l}\text { What is the criterion for the validation of a CFD simulation by a laboratory } \\
\text { experiment? } \\
\text { a. If the difference between the CFD and experimental data is less than } \\
\text { the convergence limit. } \\
\text { b. If the difference between the CFD and experimental data is less than } \\
\text { the CFD data uncertainties. } \\
\text { c. If the difference between the CFD and experimental data is less than } \\
\text { the experimental data uncertainties. } \\
\text { d. If the difference between the CFD and experimental data is less than } \\
\text { the combination of the experimental and CFD data uncertainties. }\end{array}$ \\
\hline
\end{tabular}

Table 11. Examples of test questions

\begin{tabular}{|c|c|c|c|c|}
\hline \multicolumn{2}{|c|}{ Pre-test } & \multicolumn{2}{|c|}{ Post-test } & $\mathrm{N}$ \\
\hline $\bar{x}_{\text {pre }}$ & $\sigma_{\text {pre }}^{2}$ & $\bar{x}_{\text {post }}$ & $\sigma_{\text {post }}^{2}$ & \multirow{2}{*}{35} \\
7.35 & 5.28 & 15.87 & 4.94 & \\
\hline
\end{tabular}

Table 12. Mean number of correct answers (out of 20)

The success of this introduction could not be assessed using a student comparison performance in CFD laboratories across the years as these data were not available or not in a form that would make for meaningful comparison. This is not necessarily a weakness of the study as it has been suggested (Lucas, 1997) that the measurements of differences in student assessment over time has limited value given the changing nature of student cohorts from one year to another. On the basis of these recommendations a questionnaire was developed to elicit perceptions of the introduction of CFD from students involved in the class. 


\subsection{Online questionnaire}

An anonymous online survey was conducted after students obtained their grades for the laboratory reports to aid formative evaluation of the introduction of CFD. Only students who had completed the course with CFD were surveyed. A questionnaire using 11 statements as listed in Table 13 was designed for this survey. Students were requested to respond to each item in the questionnaire using a five-point scale: strongly agree, agree, neutral, disagree and strongly disagree plus a column for no opinion. An opportunity was also provided for students to comment on their experience at the end of the questionnaire to collect qualitative feedback on their experience so far with CFD.

\begin{tabular}{|c|c|}
\hline No. & Question/Statement \\
\hline 1 & I found the software easy to use. \\
\hline 2 & I have used CFD modelling before. \\
\hline 3 & This CFD tool enhances my understanding of the theory course. \\
\hline 4 & This CFD tool is a useful addition to the fluid mechanics laboratories. \\
\hline 5 & The 'hands-on' aspects of the CFD tool has taught me extra skills. \\
\hline 6 & $\begin{array}{l}\text { The 'hands-on' aspects of the CFD tool has given me deeper knowledge of fluid } \\
\text { mechanics. }\end{array}$ \\
\hline 7 & $\begin{array}{l}\text { On using CFD I have learned things that could not be taught through the theory or } \\
\text { experimental courses. }\end{array}$ \\
\hline 8 & I now have a knowledge of CFD procedures and methodology. \\
\hline 9 & I feel I could now continue to model basic flows. \\
\hline 10 & $\begin{array}{c}\text { On completion of this course I have run at least one flow simulation with the software } \\
\text { provided. }\end{array}$ \\
\hline 11 & I would recommend the CFD laboratory to others. \\
\hline
\end{tabular}

Table 13. A list of questions/statements used in the survey for students' feedback

Generally, student feedback surveys have a very low response rate (Gamliel \& Davidovitz, 2005; Nulty, 2008). However the response rate here was high $(>80 \%)$ with 5 responses received per question and overall, the results from the survey were positive. The responses to the survey are shown on Fig. 7 and indicate that students felt that they benefited from their exposure to CFD. In additional comments most of the students expressed the view that the amount of material introduced was correct, although some felt that the exercises took a long time to complete correctly. Students were particularly appreciative that they could easily visualize flow using contour and vector plots and generally agreed that the combination of theory, experimental and CFD led to better understanding of fluid mechanics. Students also showed enthusiasm for learning more about CFD.

In addition to the questionnaire of Table 13, the students were asked "Would you recommend that CFD remains in the fluid mechanics course in the future?" To this $82 \%$ said yes so showing that they thought CFD as having a positive impact on their studies. 


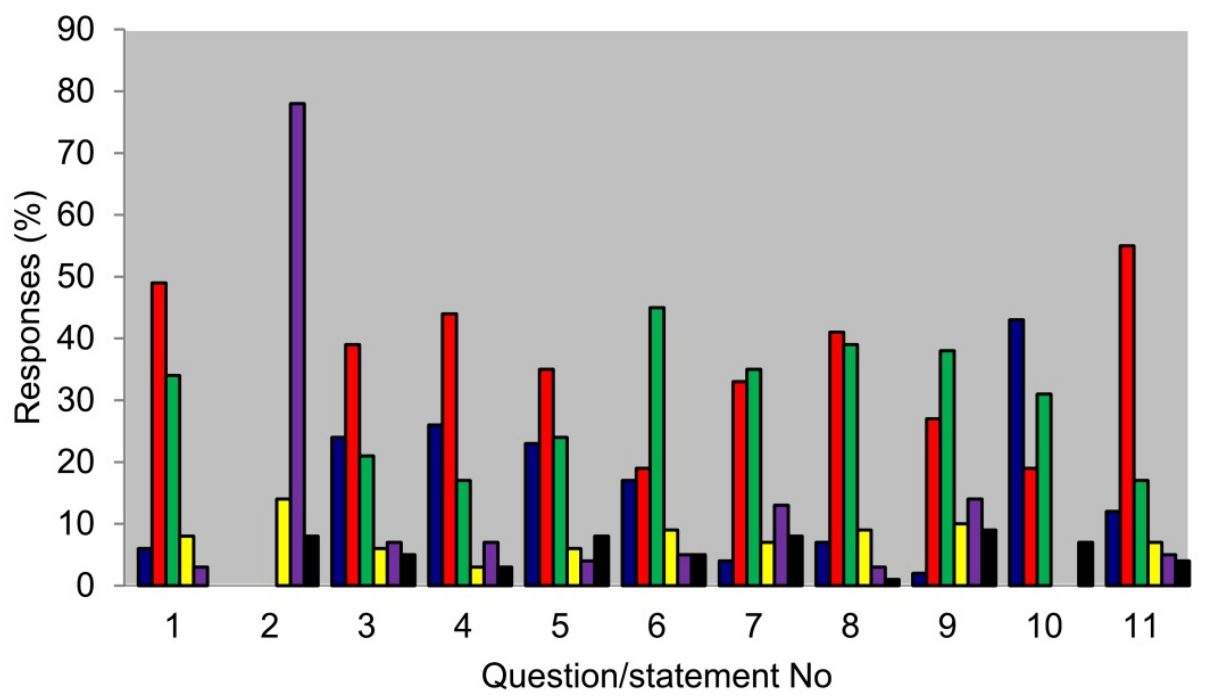

$\square$ Strongly agree $\square$ Agree $\square$ Neutral Disagree $\square$ Strongly disagree $\square$ No opinion

Figure 7. Chart showing survey results $(\mathrm{N}=55)$

It was noted that the students liked the hands-on and self-discovery approach, although at times some frustration was also noted. Once a demonstration was given there was only an interest to learn by themselves, back up when required by a Teaching Assistant's advice. The traditional view of CFD is that it has a steep learning curve, but with a structures CFD interface and with limited depth imposed it has been demonstrated that the gradient of the curve can be brought to an acceptable level.

Of course, during the skills training at this level, no real mention was made of code development, as the purpose was to develop users of the code only. This can be remedied by a later course which improves the student as a user and starts showing ways of writing new code for special conditions. Actually the software used here has a module which can translate simple instructions into FORTRAN. The concept to represent this software package or any other package as a black box should be remedied as soon as possible in later courses.

\section{Concluding remarks}

This paper has described the use and efficacy of integrating computational fluid dynamics into a traditional fluid mechanics course. The controlled experiment has shown that the inclusion of CFD laboratories gave students a better appreciation of fluid mechanics in general and the students gained better knowledge of simple concepts. However, the inclusion of CFD laboratories had a detrimental effect on interest when compared to the purely experimental control group and the control group also did better when considering the more difficult aspects of the course. It was found from the study of student knowledge 
and skill outcomes for the CFD interface that the students could cope with CFD reasonably well, provided the subject is introduced with care. One of the main reasons for the inclusion of CFD was to contribute to the teaching of professional practice skills to intermediate level undergraduate students. It was found that the interface design does provide students with hands-on experience, gained through an interactive and user-friendly environment, and encourages student self-learning. It was noted from the survey that the students liked the hands-on and self-discovery approach, although at times some frustration was also noted.

\section{Author details}

Desmond Adair

University of Tasmania, Australia

\section{References}

Aradag, S., Cohen, K., Seaer, C.A. \& McLaughlin, T. (2009). Integration of Computations and Experiments for Flow Control Research with Undergraduate Students, Computer Applications in Engineering Education, Vol. 17, No. 1, pp. 1 -11.

Agonafer, D., Liao, D.G. \& Spalding, B. (2008). The LVEL turbulence Model for Conjugate Heat Transfer at Low Reynolds Numbers, Concentration, Heat and Momentum Ltd., London, UK.

Assanis, D.N. \& Heywood, J.B. (1986). Development and Use of a Computer Simulation of Turbocompounded Diesel System for Engine Performance and Component Heat Transfer Studies, SAE Transactions, Vol.2, pp. 451-476.

Campbell, J.O., Bourne, J.R., Mosterman, P.J., Nahni, M., Rassai, R., Brodersen, A.J. \& Dawant, M. (2004). Cost-effective Distributed Learning with Electronics Labs, Journal of Asynchronous Learning Networks, Vol. 8, No. 3, pp. 5-10.

Cohen, J. (1988). Statistical Power Analysis for the Behavioral Sciences (2 ${ }^{\text {nd }}$ ed.). Hillsdale, NJ: Lawrence Earlbaum Associates.

Devenport, W.J. \& Schetz, J.A. (1998). Boundary Layer Codes for Students in Java, Proceedings of FEDSM'98, ASME Fluids Engineering Division, Summer Meeting, Washington DC, June, pp. 21-25.

Feisel, L.D. \& Rosa, A.J. (2002). The Role of the Laboratory in Undergraduate Engineering Education, Journal of Engineering Education, Vol. 91, No. 1, pp. 121-130.

Ferziger, J. H. \& Peric, M. (1996). Computational Methods for Fluid Dynamics, Springer, New York.

Gamliel, E. \& Davidovitz, L. (2005). Online Versus Traditional Teaching Evaluation: Mode Can Matter, Assessment \& Evaluation in Higher Education, Vol. 30, No. 6, pp. 581- 592.

Hung, T.C., Wang, S.K., Tai, S.W. \&Hung, C.T. (2005). An Innovative Improvement in Engineering Learning System using Computational Fluid Dynamics Concept, Computer Applications in Engineering Education, Vol. 13, No. 4, pp. 306-315.

Keller, C.J., Finkelstein, N.D., Perkins, K.K. \& Pollock, S.J. ((2007). Assessing the Effectiveness of a Computer Simulation in Introductory Undergraduate Environments, AIP Conference Proceedings, Vol. 883, pp. 121-124. 
Kelsey, R. (2001). Brownfield Action: An Integrated Environmental Science Simulation Experience for Undergraduates, Annual Proceedings of Selected Research and Development, Atlanta, GA, Nov. 8-12.

LaRoche, R.D., Hutchings, B.J. \& Muralikrishnan, R. (2002). FlowLab: Computational Fluid Dynamics (CFD) Framework for Undergraduate Education, Proceedings of the 2002 ASEE/SEFI/TUB Colloquium, Berlin, Oct. 1-4.

Launder, B.E. \& Spalding, B. (1972). Mathematical Models of Turbulence, Academic Press. London.

Likert, R. (1932). A Technique for the Measurement of Attitude, Archives of Psychology, Vol. 22, No. 140.

Lucas, U. (1997). Active Learning and Accounting Educators, Accounting Education, Vol. 6, pp. 189-190.

Nulty, D.D., The Adequacy of Response Rates to Outline and Paper Surveys: What can be Done? Assessment \& Evaluation in Higher Education, Vol. 33, No. 3, pp. 301-314.

Patil, A., Mann, L, Howard, P. \& Martin, F. (2009). Assessment of Hands-On Activities to Enhance Students' Learning in the First Year Engineering Skills Course, 20 th Australasian Association for Engineering Education Conference, Univ. Of Adelaide, 6-9 Dec., pp. 286-292.

Pfahl, D., Laitenberger, O., Ruhe, G., Dorsch, J. \& Krivobokova, T. (2004). Evaluating the Learning Effectiveness of Using Simulations in Software Project Management Education: Results from a Twice Replicated Experiment, Information \& Software Technology, Vol. 46, pp. 127-147.

Pieritz, R.A., Mendes, R., Da Sila, R.F.A.F. \& Maliska, C.R. (2004). CFD: An educational Software Package for CFD Analysis and Design, Computer Applications in Engineering Education, Vol. 12, No. 1, pp. 20-30.

Qian, X. \& Tinker, R. (2006). Molecular Dynamics Simulations of Chemical Reactions for Use in Education, Journal of Chemical Education, Vol. 81, No. 1, pp. 77-90.

Ray, J.W. \& Shadish, W.R. (1996). How Interchangeable are Different Estimators of Effect Size? Journal of Consulting and Clinical Psychology, Vol. 64, pp.1316-1325. (see also: (1998) Correction to Ray and Shadish, Journal of Consulting and Clinical Psychology, Vol. 66, pp.532.)

Rozza, G., Huynh, D.B.P., Nguyen, N.C. \& Patera, A.T. (2009). Real-Time Reliable Simulation of Heat Transfer Phenomena, ASME-American Society of Mechanical Engineers - Heat Transfer Summer Conference, Paper HT2009-88212, San Franscisco, USA, July 1923.

Stern, F., Xing, T., Yarbrough, D.B., Rothmayer, A., Rajagopalan, G., Otta, S.P., Caughey, D., Bhaskaran, R., Smith, S., Hutchings, \& B., Moeykens, S. (2006). Hands-On CFD Educational Interface for Engineering Courses and Laboratories, Journal of Engineering Education, Vol. 95, No. 1, pp. 63-83.

Tu, J., Yeoh, G. H. \& Liu, C. (2007). Computational Fluid Dynamics - A Practical Approach, Elsevier, Amsterdam.

Zheng, H. \& Keith, J.M. (2003). Web-Based Instructional Tools for Heat and Mass Transfer, ASEE Conference Proceedings, June. 